\title{
A TASMAN Expedition: Development of a Questionnaire to Assess Specific Self-Management Abilities
}

This article was published in the following Dove Press journal: International Journal of Chronic Obstructive Pulmonary Disease

\author{
M Voorhaar (1D \\ $\mathrm{J}_{\text {Tiemensma }}^{2}$ \\ GM Asijee' \\ AHM Slok' \\ JWM Muris $\mathbb{D}^{1}$ \\ AA Kaptein $\left(\mathbb{D}^{3}\right.$
}

'Department of Family Medicine, Maastricht University, CAPHRI Care and Public Health Research Institute, Maastricht, the Netherlands;

${ }^{2}$ Department of Anesthesiology, Erasmus University Medical Center, Rotterdam, the Netherlands; ${ }^{3}$ Department of Medical Psychology, Leiden University Medical Centre, Leiden, the Netherlands

Correspondence: M Voorhaar

Email m.voorhaar@maastrichtuniversity.nl
Introduction: Self-management (SM) is a core component of well-being and perceived health for patients with chronic obstructive pulmonary disease (COPD). Most theories on SM share that self-efficacy, illness-perception and coping are determinants of SM behavior. Optimal support to improve SM should be tailored to the individual patient's level of these determinants as SM abilities vary between patients. To tailor SM support, it is therefore necessary to assess the scores on these determinants. Unfortunately, no such instrument exists for clinical use. Therefore, the first goal of this study was to verify presumed correlations between SM and the determinants thereof. The second goal was to develop an instrument to assess the SM abilities.

Methods: In this cross-sectional, observational study, COPD patients completed the General Self-Efficacy Scale (GSES), Brief Illness Perception Questionnaire (B-IPQ) and the Utrecht Proactive Coping Competence measure (UPCC) as well as the Self-Management Ability Scale (SMAS-30). Correlations between the questionnaires were assessed and a principal component analysis (PCA) was performed to identify the best-fitting items in the three independent variables related to SM. These items were used to create an instrument to assess SM abilities.

Results: Hundred COPD patients (58 males, 41 females, 1 unknown) were included. The correlation between SM and self-efficacy, illness perception on concerns and proactive coping was moderate and significant $(\mathrm{r}=0.318, \mathrm{p}<0.01 ; \mathrm{r}=-.230, \mathrm{p}<0.05 ; \mathrm{r}=.426, \mathrm{p}<0.01$, respectively). PCA identified six UPCC items and nine GSES items that met the predefined criteria. These items were supplemented with the B-IPQ concerns item to establish the new instrument to assess SM abilities.

Keywords: self-management, validation, patient-reported outcome, chronic disease, personalized medicine

\section{Introduction}

Self-management is a core component of well-being and perceived health for patients with a chronic condition. Most chronic conditions, such as cardiovascular disease, diabetes mellitus, and chronic obstructive pulmonary disease (COPD) share common challenges associated with their medical management. These include dealing with symptoms and disability; the need for monitoring specific physiological indicators; management of complex medication regimens; maintaining proper levels of nutrition and exercise; adjusting to the psychological and social demands, including difficult lifestyle adjustments; and engaging in effective interactions with 
health care providers. ${ }^{1,2}$ Ultimately, care should lead to better patient outcomes, but a biomedical focus only led by healthcare providers will be insufficient to improve these outcomes, as patients have to live and cope with their illness every day. By improving patient activation, it is expected that patients will be actively involved in coping with and managing their illness, even when they do not see their physician. Ample evidence shows that better selfmanagement abilities are related with higher self-reported health outcomes. ${ }^{3,4}$ However, there is a diversity in selfmanagement abilities; some patients are better able to selfmanage than others. ${ }^{5,6}$ There are those who anticipate situations that might negatively influence the course of their condition and act on this, while there are patients who are more passive, unable or unwilling to act. Furthermore, not all patients respond equally to similar self-management interventions; the same intervention results in different outcomes in patients with a similar condition. ${ }^{7}$ This variation between patients is not surprising as health behavior depends on different determinants thereof, which are overlapping with self-management behavior. According to the Common Sense Model of Health (CSM), self-efficacy, illness perception and coping are the main determinants of self-management behavior. ${ }^{8-10}$ The key component of this model is that patients develop mental constructs about their illness and its treatability. These mental constructs determine the actions patients take when confronted with threats to their health. Consequently, these actions are monitored and assessed for effectiveness on the course of their illness and thus influence future coping strategies, also called pro-active coping. In turn, this influences the representations of health and disease. This is a rather complex mechanism where different mental constructs interact with one another while being under influence of other factors, ie, media presentations on illness and personal observations of other patients and their different coping mechanisms. As a result, there is no clear consensus to point out a single determinant of selfmanagement. What is clear is that to improve self-management, a single determinant focus is unlikely to result in the same effect in every patient.

To optimize self-management support, we hypothesize that this support should be tailored to the patient's level of these determinants. If an instrument to assess these determinants of self-management abilities exists, tailored support would be possible. The Self-Management Ability Scale (SMAS-30) was developed to identify patients' ability to self-manage on six different inter-related domains related to well-being of the elderly. ${ }^{11}$ This questionnaire was recently utilized in a COPD population, where a positive relationship between SMAS scores and quality of life was found. ${ }^{12}$ However, the SMAS-30 does not assess determinants of health behavior. There are questionnaires that measure the individual determinants of self-management, such as self-efficacy measured by the General Self-efficacy Scale (GSES), illness perceptions measured by the Brief Illness Perception Questionnaire (B-IPQ) and pro-active coping measured by the Utrecht Proactive Coping Competence scale (UPCC). In daily practice, physicians have limited time to address selfmanagement behavior and perform mainly biomedical check-ups. To be efficient within this limited time to assess self-management abilities, a robust and short informative questionnaire is needed. Therefore, the study has two goals: The first goal of this study is to explore correlations between self-management and the different determinants of health behavior. The second goal is to develop a clinically useful instrument to assess these determinants of self-management behavior. Such an instrument should make it possible for healthcare providers to tailor their self-management support based on the level of the abilities of patients. This instrument should be short to administer and easy to interpret for it to be considered clinically useful.

\section{Patients and Methods}

In this cross-sectional, observational study, four community pharmacists randomly selected patients from their database fulfilling the inclusion criteria. These patients were contacted by phone to inform them about the study and inquire about their interest to participate. Interested patients were invited to the pharmacy where they received an information leaflet on the study and an informed consent form. After signing the consent form, patients received the study questionnaires with instructions on how to complete and return them. The Medical Ethical Committee of the University of Leiden approved this study (P11.170).

Because this was a pilot study, a single patient population with a common chronic disease like COPD was selected to enhance the likelihood of including sufficient participants. There is no clear guidance on sample size calculations in validation studies on self-reported questionnaires (Tsang et al 2016). Also, in a literature review performed to assess sample sizes validation studies for patient-reported outcome measures, it was found that 
over $90 \%$ of the studies had a minimum of 100 participants. ${ }^{15}$ Therefore, it was decided pragmatically to recruit 100 participants.

\section{Patients}

Inclusion criteria were age $>40$ years, being diagnosed with COPD at least one year prior to study participation, and using airway medication for at least a year. Patients were excluded if they were deemed unable to complete the questionnaires due to cognitive impairments or because of low literacy.

\section{Measurements}

Demographics, Illness Severity and Quality of Life

Age, highest level of education, date of diagnosis of COPD, perceived severity of COPD and perceived quality of life data were obtained from participating patients; all had signed the informed consent form. The level of education was categorized in "low" (only primary school), "medium" (high school diploma or community college) or "high" (bachelor or university degree). Severity of COPD was measured by using a Visual Analogue Scale (VAS), scored on a line of 100 millimeters representing a score of 0 to 100,0 being least severe and 100 most severe. Health-related quality of life (HRQoL) was assessed with a single item: "Could you indicate, generally speaking, how your quality of life is?" similar to the EuroQol visual analogue (EQ VAS).$^{13}$ Patients were presented a 100-millimeter VAS ranging from 0 (bad) to 100 (good). A higher score on this item indicates a better HRQoL.

\section{General Self-Efficacy Scale (GSES)}

To assess self-efficacy, we used the General Self-Efficacy Scale (GSES). This questionnaire consists of 10 items, scored on a 4-point Likert scale (eg, "I can always manage to solve difficult problems if I try hard enough."). The items are summed to calculate the total score, where higher scores indicate higher levels of self-efficacy. The internal consistency for the Dutch GSES is high; $\alpha=0.86{ }^{16}$

\section{Brief Illness Perception Questionnaire (B-IPQ)}

We used the Dutch version of the Brief Illness Perception Questionnaire (B-IPQ), intended to assess cognitive and emotional representations of illness. It consists of eight single-item scales where each item is scored on a 10point Likert scale. Five items assess cognitive illness perceptions (eg, "How much do you think your treatment can help your illness?"), two items assess emotional perceptions (eg, "How much does your illness affect you emotionally?"), and one item assesses illness coherence ("How well do you feel you understand your illness?"). In addition, one open question asks participants to list the three main causal factors for their illness, as perceived by the participant. The B-IPQ has good concurrent validity and predictive validity for each individual perception but averaging a mean score is not advised. ${ }^{17}$

\section{Utrecht Proactive Coping Competence Scale (UPCC)}

We used the Utrecht Proactive Coping Competence scale (UPCC) to assess proactive coping. This questionnaire consists of 21 items where each item is scored on a 1-4 Likert scale (eg, "To what extent do you have the capacity to recognize signals that something might go wrong?"). The provided score represents the level of proficiency in proactive coping, from low to high. The scale has been validated and has been found to be reliable in differentiating between patients high and low in proactive competencies $(\alpha=0.89){ }^{18}$

\section{Self-Management Abilities Scale (SMAS-30)}

The Self-Management Abilities Scale (SMAS-30) is a questionnaire to assess self-management abilities (SMA) in a generic population. SMA is defined as the core behavioral and cognitive abilities related to well-being. ${ }^{11}$ The SMAS-30 consists of 30 items distributed over 6 inter-related abilities, 5 items per ability: Multifunctionality (eg, "The activities I enjoy, I do together with others."), Variety (eg, "How many hobbies or activities do you have on a regular basis?"), Positive Frame of Mind (eg, "How often are you able to see the positive side of the situation when something disagreeable happens?"), Investment Behavior (eg, "Do you ensure that you have enough interests on a regular basis (such as a hobby) to keep you active?"), Self-efficacy (eg, Are you able to find agreeable activities?") and Taking Initiatives (eg, "How often do you take the initiative to keep yourself busy?"). All items were scored on a 5-point Likert scale. The sub-scales are closely related to each other, but do not measure the same ability. All the sub-scales were unidimensional; summing their scores leads to a composite overall score. The internal consistency of the SMAS-30 is high $(\alpha=0.91)$ while Cronbach's $\alpha$ 's for the sub-scales were satisfactory as they ranged from 0.67 to $0.84 .^{11}$

\section{Analysis}

All statistical analyses were performed using IBM SPSS statistics, v25.1. The first goal of this study was to explore 
correlations between self-management and the different determinants of health behavior. The second goal was to develop a holistic instrument to assess these determinants of self-management behavior based on the selected determinants. These goals were approached in a three-step analytical plan. Step 1: to confirm the validity of the SMAS for COPD patients in the Netherlands; Step 2: to assess correlations between self-management and determinants of health behavior and Step 3: to select the most appropriate health behavior items related to self-management.

First, the psychometrics of the SMAS in this study population were assessed and compared with the psychometrics found in the validation study of the SMAS-30. Second, the correlations between self-management, self-efficacy, illness perception and proactive coping were assessed. Correlations were considered strong and relevant when Cronbach is $\alpha>$ 0.8 and when these correlations were statistically significant. If self-management indeed correlated with these determinants of self-management behavior, step 3 was taken to achieve our main goal; ie: to develop a new instrument which can assess these determinants of self-management behaviour in COPD patients. The third step entails selecting appropriate items from the questionnaires related to selfmanagement abilities. Principal component analysis (PCA) can select the most relevant items from the individual questionnaires that relate to self-management measured by the SMAS and these will construct the new questionnaire. Parallel analysis and scree plots (both carried out in R Core Team (2016), see also Appendix 1) ${ }^{19}$ were utilized to determine the number of relevant components per questionnaire. The items will be included in the final instrument if they fulfill the following criteria, similar to the development of the SMAS: ${ }^{11}$ Correlation between the individual item with the main component after component analysis $>.7$, inter-item correlations between 0.2 and 0.7 , Cronbach's $\alpha>0.8$, and an item-total correlation $>0.7$. These criteria fall in the range for guidelines to develop questionnaires. ${ }^{13}$ In the analyses in steps 1 and 2, as well as the parallel analysis and scree plots, missing data were excluded list-wise. For the PCA, missing data were excluded pairwise.

\section{Results}

Hundred COPD patients (58 males, 41 females, 1 unknown) were included in the study with a mean age of 70 years. On average, the mean self-reported perceived severity of their COPD was 39.27 indicating a relatively low burden of disease. Most patients (75\%) reported completing either low or medium education, see Table 1.
Table I Main Patient's Characteristics

\begin{tabular}{|l|l|}
\hline Characteristics & COPD (N=100) \\
\hline Sex (male/female) & $58 / 4$ I (n=I unknown) \\
Age (years) & $69.68 \pm 9.74$ \\
\hline Educational level & Low: $36(36 \%)$ \\
& $\begin{array}{l}\text { Medium: } 39(39 \%) \\
\text { High: } 23(23 \%) \\
\text { Unknown: } 2(2 \%)\end{array}$ \\
\hline COPD duration & I-3 years: $20(20 \%)$ \\
& $\begin{array}{l}\text { More than } 3 \text { years: } 75(75 \%) \\
\text { Unsure: } 5(5 \%)\end{array}$ \\
\hline Self-reported COPD severity & $39.27 \pm 26.3$ \\
\hline
\end{tabular}

Abbreviation: COPD, chronic obstructive pulmonary disease.

\section{Mean Scores of Determinants of Self- Management Behavior}

The mean scores on the GSES and UPCC were, respectively, $3.15(\mathrm{SD}=0.55)$ and $2.97(\mathrm{SD}=0.45)$, comparable to the mean score on the GSES (3.3, SD=0.5) found by Talboom-Kamp and colleagues ${ }^{20}$ and to the mean score on the UPCC (3.0, $\mathrm{SD}=0.4$ ) found by Weldam and colleagues. ${ }^{21}$ The mean score for the SMAS was $62.11(\mathrm{SD}=11.76)$, lower than the mean score $(67.83, \mathrm{SD}=11.55)$ found by Benzo and colleagues. ${ }^{12}$ No mean score for the B-IPQ was calculated in our study.

\section{Step I: Psychometric Properties of SMAS}

The psychometric data of our population were compared to the psychometric data from the original validation study of the SMAS-30. ${ }^{11}$ Cronbach's $\alpha$ of the SMAS-30 was comparable in both studies ( 0.91 vs 0.87 ). Inter-item correlations of the subscales showed comparable results in our study, compared to the original validation study ${ }^{11}$ except for the subscale Variety. The Variety subscale had an inter-item correlation of 0.67 in the original study, whereas in our study this correlation was 0.39 . Principal component analysis performed on our study data indicated that the SMAS-30 consists of eight components of which two main components explain $41.4 \%$ of its variance, comparable to the results from the component analysis performed in the study by Schuurmans et al. ${ }^{11}$

\section{Step 2: Correlations Between Determinants of Self-Management Behavior and Self- Management}

The correlation between the GSES and UPCC was moderate and significant $(\mathrm{r}=0.569, \mathrm{p}<0.001)$. The correlations between the GSES and individual components of the B-IPQ were 
significant yet weak and negative for concerns and coherence $(\mathrm{r}=-0.239, \mathrm{p}=0.02, \mathrm{r}=-0.225, \mathrm{p}=0.027)$ while the correlation between the GSES and B-IPQ emotions was non-significant, positive and weak $(r=0.268, p=0.08)$. There was no significant correlation between the UPCC and any of the individual components of the B-IPQ.

The correlation between both self-efficacy (GSES) and self-management abilities (SMAS-30) as well as for proactive coping (UPCC) and self-management abilities (SMAS30) were moderate and significant: $\mathrm{r}=0.318, \mathrm{p}<0.01 ; \mathrm{r}=.426$, $\mathrm{p}<0.01$, respectively. The only significant illness perception question that correlated with self-management was patients' concerns about their disease: indicating that patients who are less concerned about their illness are better able to selfmanage $(\mathrm{r}=-.230, \mathrm{p}<0.05)$, see Table 2 .

\section{Step 3: Principal Component Analysis}

As pro-active coping and self-efficacy were found to be related to self-management, items best related to its construct were identified through Principal Component Analysis (PCA). Parallel analyses and scree plots indicated one component for each of the two surveys. PCA extracted these components of the UPCC and the GSES, see Appendix 2. As only one illness perception was found to be related to self-management, no further PCA was necessary.

\section{Item Selection}

Six items from the UPCC and nine items from the GSES had factor loadings $>0.7$ for the extracted component (with eigenvalue $>1$ ). In addition to eigenvalue considerations, we conducted parallel analyses and utilized screen plots (Appendix 2). Based on these, we came to the conclusion that only one component per survey should be evaluated. The inter-item correlations of the selected

Table 2 Correlations Between Self-Management Abilities, SelfEfficacy and Illness Perception and Proactive Coping

\begin{tabular}{|c|c|c|c|c|}
\hline & & GSES & $\begin{array}{l}\text { IPQ- } \\
\text { CONCERNS }\end{array}$ & UPCC \\
\hline $\begin{array}{l}\text { SMAS } \\
\text { TOTAL }\end{array}$ & $\begin{array}{l}\text { Pearson } \\
\text { Correlation } \\
\text { Sig. (2-tailed) } \\
\mathrm{N}\end{array}$ & $\begin{array}{l}.318^{*} \\
0.001 \\
98\end{array}$ & $\begin{array}{l}-.230 * * \\
0.026 \\
94\end{array}$ & $\begin{array}{l}.426 * \\
0 \\
97\end{array}$ \\
\hline
\end{tabular}

Notes: *Correlation is significant at the 0.01 level $\left(2\right.$-tailed). ${ }^{* *}$ Correlation is significant at the 0.05 level (2-tailed).

Abbreviations: SMAS, Self-Management Ability Scale; GSES, General Self-Efficacy Scale; IPQ- concerns, IIIness Perception Questionnaire Concerns; UPCC, Utrecht Proactive Coping Competence scale. items from the UPCC ranged between 0.444 and 0.677 ; for the selected items from the GSES the inter-item correlations varied between 0.379 and 0.679 , see Table 3 and Appendix 3. Cronbach's $\alpha$ for the selected items from the UPCC was 0.894; for selected items from the GSES it was 0.915. The item-total correlation between the selected items from the UPCC and its total score was $>0.866$; for the selected items from GSES and its total score from these items was $>0.903$. As the results from the dataanalysis met the aforementioned criteria, ${ }^{14}$ six items from the UPCC and nine items from the GSES were selected to form the new instrument. The single item from the B-IPQ, concerns, was added separately to the final questionnaire, as no further analysis was deemed appropriate for a single item.

\section{Correlation Between Determinants and Final Instrument}

To score the final instrument: recode question 16 to a 4point scale ( 0 and 1 are recoded to $1,2-4$ are recoded to 2 , 5-7 are recoded to 3 , and $8-10$ are recoded to 4$)$. Next, add Q1 through Q16. The total score can range from 16 to 64. In the present sample, the mean score on the final instrument was 49.45 ( $\mathrm{SD}=7.53$, range $=23$ to 63 , normal distribution).

The correlation between the final instrument total score and the original SMAS were moderate and significant; $\mathrm{r}=0.320(\mathrm{p}<0.01)$. As expected, the correlation between the UPCC and GSES and the total score from the final instrument were strong and significant: $\mathrm{r}=0.821, \mathrm{p}<0.005$ and $\mathrm{r}=0.884, \mathrm{p}<0.005$, respectively. The final instrument is represented in Figure 1, and is called the TASMAN, an acronym for TAilored measurement for Self-Management Abilities in the Netherlands. In Figure $1 \mathrm{~m}$ item 16 is recoded to a 4-point Likert scale to match the other items. In Appendix 4, item 16 is included in its original scale (11-point Likert scale) to the TASMAN instrument.

\section{Discussion}

The results from this study indicate that the developed questionnaire is a promising new instrument to self-assess self-management abilities. This study showed that patients' self-assessed self-efficacy, concerns about their disease and proactive coping, are related to self-management abilities. Additionally, through component analysis we minimized the set of relevant questions to identify the determinants, creating an instrument with a minimal number of questions, which should be easy to use in daily practice. 
Table 3 Inter-Item Correlations Selected Items

\begin{tabular}{|c|c|c|c|c|c|c|c|c|c|}
\hline & UPCC_5 & UPCC_6 & UPCC_8 & UPCC_9 & UPCC_I2 & UPCC_I7 & & & \\
\hline UPCC_5 & I & 0.604 & $0.47 I$ & 0.444 & 0.562 & 0.528 & & & \\
\hline UPCC_6 & 0.604 & 1 & 0.53 & 0.544 & 0.669 & 0.535 & & & \\
\hline UPCC_8 & 0.471 & 0.53 & I & 0.677 & 0.533 & 0.634 & & & \\
\hline UPCC_9 & 0.444 & 0.544 & 0.677 & 1 & 0.671 & 0.654 & & & \\
\hline UPCC_12 & 0.562 & 0.669 & 0.533 & 0.671 & I & 0.622 & & & \\
\hline \multirow[t]{2}{*}{ UPCC_I7 } & 0.528 & 0.535 & 0.634 & 0.654 & 0.622 & I & & & \\
\hline & GSES_I & GSES_3 & GSES_4 & GSES_5 & GSES_6 & GSES_7 & GSES_8 & GSES_9 & GSES_10 \\
\hline GSES_I & I & 0.575 & 0.566 & 0.521 & 0.633 & 0.482 & 0.424 & 0.392 & 0.539 \\
\hline GSES_3 & 0.575 & I & 0.618 & 0.495 & 0.679 & 0.503 & 0.401 & 0.453 & 0.447 \\
\hline GSES_4 & 0.566 & 0.618 & I & 0.531 & 0.624 & 0.508 & 0.543 & 0.601 & 0.478 \\
\hline GSES_5 & 0.521 & 0.495 & 0.531 & I & 0.547 & 0.566 & 0.631 & 0.661 & 0.61 \\
\hline GSES_6 & 0.633 & 0.679 & 0.624 & 0.547 & I & 0.567 & 0.501 & 0.466 & 0.527 \\
\hline GSES_7 & 0.482 & 0.503 & 0.508 & 0.566 & 0.567 & I & 0.509 & 0.674 & 0.568 \\
\hline GSES_8 & 0.424 & 0.401 & 0.543 & 0.631 & 0.501 & 0.509 & I & 0.661 & 0.542 \\
\hline GSES_9 & 0.392 & 0.453 & 0.601 & 0.661 & 0.466 & 0.674 & 0.661 & 1 & 0.623 \\
\hline GSES_10 & 0.539 & 0.447 & 0.478 & 0.61 & 0.527 & 0.568 & 0.542 & 0.623 & I \\
\hline
\end{tabular}

Abbreviations: UPCC, Utrecht Proactive Coping Competence scale; GSES, General Self-Efficacy Scale.

In our study, we found that the Common Sense model proved to be a useful theoretical framework to develop this instrument. Patients who scored higher on the GSES, IPQ concerns and UPCC, also scored higher on the SMAS, indicating that patients who were more self-efficacious, ie, had more confidence in their own abilities, also had better self-management abilities. Similarly, patients who had less concerns about their disease were more likely to report better self-management abilities. Furthermore, patients who were better able to adjust their current behavior based on expected events in the future were better able to self-manage. The strong relationship between selfefficacy, concerns about illness, proactive coping and selfmanagement is not surprising; many theoretical models, including Ajzen's theory of planned behavior, ${ }^{22,23}$ Bandura's social cognitive theory, ${ }^{22,23}$ and Leventhal's Common Sense model of Illness perception, ${ }^{9,22}$ indicate that self-efficacy, illness perception and coping are crucial components to determine the ability to self-manage. Moreover, two studies showed, that a self-management program based on improving proactive coping abilities, led to better self-management. ${ }^{24,25}$

A strong point in our study was that, similar to the development of the SMAS, ${ }^{11}$ data-analysis was the basis to identify the best-fitted items for the new questionnaire. Our method was also congruent with widely accepted guidelines on the development of questionnaires. ${ }^{13}$ By using similar methods and guideline principles, we minimized the risk that confounding factors or potentially investigator bias negatively influenced the results.

As this was a cross-sectional study, we could not perform all required validity assessments in a single study. For one, test-retest repeatability could not be performed as this would require follow-up measures. This would only be possible after construction of the instrument. Furthermore, we did not measure any possible change in self-management over time. At this stage of our research, we are not able to state whether the TASMAN questionnaire would be able to detect change. Furthermore, we did not perform a confirmatory analysis. We will, however, do this analysis in a follow-up study where the instrument is tested for test-retest repeatability, in a comparable cohort. It is known that patients who selfmanage well are more inclined to participate in research, which makes it difficult to generalize outcomes outside of the studied population. As we did not actively prevent this selection bias, we cannot rule out that our results were influenced by this phenomenon. We do believe that the measured concepts were well studied in different populations and we do not expect that the results would be different when less self-managing patients participated in this study. Nevertheless, we would suggest replicating the study in a comparable COPD population as well as in a population of patients with other chronic diseases, like asthma or diabetes mellitus. Even though the causes and medical consequences might be different in these different diseases, the underlying health behaviour is universal, and patients need to optimize 


\begin{tabular}{|c|c|c|c|c|c|}
\hline \multicolumn{2}{|c|}{$\begin{array}{l}\text { To which extent do you have the following } \\
\text { capacities? }\end{array}$} & \multirow{2}{*}{$\begin{array}{c}\text { Not } \\
\text { competent } \\
1\end{array}$} & \multirow{2}{*}{$\begin{array}{c}\text { Barely } \\
\text { competent } \\
2\end{array}$} & \multirow{2}{*}{$\begin{array}{c}\text { Competent } \\
3\end{array}$} & \multirow{2}{*}{\begin{tabular}{|c|} 
Very competent \\
4
\end{tabular}} \\
\hline 1 & $\begin{array}{l}\text { See my own possibilities and } \\
\text { opportunities }\end{array}$ & & & & \\
\hline 2 & See my own limitations. & 1 & 2 & 3 & 4 \\
\hline 3 & Clearly formulate what I want to achieve. & 1 & 2 & 3 & 4 \\
\hline 4 & To translate my desires to plans & 1 & 2 & 3 & 4 \\
\hline 5 & To find solutions & 1 & 2 & 3 & 4 \\
\hline 6 & $\begin{array}{l}\text { Check if I have achieved what I want to } \\
\text { achieve. }\end{array}$ & 1 & 2 & 3 & 4 \\
\hline & & Not at all true & Hardly true & Moderately true & Exactly true \\
\hline 7 & $\begin{array}{l}\text { I can always manage to solve difficult } \\
\text { problems if I try hard enough. }\end{array}$ & 1 & 2 & 3 & 4 \\
\hline 8 & $\begin{array}{l}\text { It is easy for me to stick to my aims and } \\
\text { accomplish my goals. }\end{array}$ & 1 & 2 & 3 & 4 \\
\hline 9 & $\begin{array}{l}\text { I am confident that I could deal efficiently } \\
\text { with unexpected events. }\end{array}$ & 1 & 2 & 3 & 4 \\
\hline 10 & $\begin{array}{l}\text { Thanks to my resourcefulness, I know } \\
\text { how to handle unforeseen situations. }\end{array}$ & 1 & 2 & 3 & 4 \\
\hline 11 & $\begin{array}{l}\text { I can solve most problems if I invest the } \\
\text { necessary effort. }\end{array}$ & 1 & 2 & 3 & 4 \\
\hline 12 & $\begin{array}{l}\text { I can remain calm when facing difficulties } \\
\text { because I can rely on my coping abilities. }\end{array}$ & 1 & 2 & 3 & 4 \\
\hline 13 & $\begin{array}{l}\text { When I am confronted with a problem, I } \\
\text { can usually find several solutions. }\end{array}$ & 1 & 2 & 3 & 4 \\
\hline 14 & $\begin{array}{l}\text { If I am in trouble, I can usually think of a } \\
\text { solution }\end{array}$ & 1 & 2 & 3 & 4 \\
\hline 15 & $\begin{array}{l}\text { I can usually handle whatever } \\
\text { comes my way }\end{array}$ & 1 & 2 & 3 & 4 \\
\hline & & $\begin{array}{l}\text { Not at all } \\
\text { concerned }\end{array}$ & $\begin{array}{l}\text { Somewhat } \\
\text { concerned }\end{array}$ & Concerned & Very concerned \\
\hline 16 & $\begin{array}{l}\text { How concerned are you about your } \\
\text { illness? }\end{array}$ & 1 & 2 & 3 & 4 \\
\hline
\end{tabular}

Figure I The final instrument "TASMAN"; the developed 16 questions to assess patient's self-management abilities. 
self-management behaviour. Therefore, it would be relevant to assess the psychometric properties of the final instrument with these and other chronic diseases.

In addition, even though the sample size was small, it is in line with the majority of similar studies aimed to develop patient-reported outcome measures. ${ }^{15}$ Therefore, we do not believe that a population with more patients would result in different outcomes. However, as we cannot rule this out, we suggest further validating the final instrument in a larger population where also less-self-managing patients are represented.

Due to ethical and practical reasons, as we wanted to minimize the research burden for participants, severity of COPD was measured via a Visual Analogue Scale (VAS). Ideally, existing instruments like the Clinical COPD Questionnaire (CCQ), COPD Assessment Test (CAT) or Assessment of Burden of COPD (ABC) scale should be used to assess the severity or burden of disease, and we recommend to use the $\mathrm{ABC}$ scale to further validate the final instrument. Lastly, no objective data like lung function data were collected in this study as the relevance of these data in a cross-sectional study is limited (as they are mainly intended for diagnostic purposes). However, in a follow-up longitudinal study to assess changes over time, it would be interesting to incorporate these objective data to study the relationship between determinants of self-management behaviour and the clinical course of the disease.

To further optimize the use of the instrument, we would advise to calculate total scores and compare those to with other instruments assessing quality of life, burden of disease and self-management to identify markers for clinical meaningful differences. Furthermore, the fact that the item to assess the perception of concerns about illness is scored on a different Likert scale than the other items needs to addressed in a future study to unify the response scales.

Eventually, any health intervention should lead to better health outcomes. An interesting follow-up research topic, therefore, would be to assess the practical use of the final instrument to detect self-management abilities to tailor evidence-based specific behavioral and cognitive interventions and consequently measure changes in self-management and outcomes in a long-term trial, compared to usual care.

\section{Conclusion}

The newly constructed instrument measures determinants of self-management behavior. The instrument is aimed to be of clinical use to guide healthcare providers towards more tailored self-management support. The evidence from this study is encouraging; however, more research for further validation and use in daily practice is recommended before using the instrument in a daily clinical setting. The final instrument was named TASMAN, an acronym for TAilored measurement for Self-Management Abilities in the Netherlands.

\section{Author Contributions}

MV: Study design, acquisition of subjects and data, drafted manuscript, and interpretation of data.

JT: Statistical analysis, interpretation of data and contributing refinements.

AS, GA, JM, \& AA: Study design, interpretation of data and contributing refinements.

All authors made substantial contributions to conception and design, acquisition of data, or analysis and interpretation of data; took part in drafting the article or revising it critically for important intellectual content; gave final approval of the version to be published; and agree to be accountable for all aspects of the work.

\section{Funding}

The research was supported by a grant provided by Boehringer Ingelheim bv NL. The views expressed in the paper are those of the authors.

\section{Disclosure}

MV reports grants from Boehringer Ingelheim, during the conduct of the study. MV \& GA are employees of Boehringer Ingelheim $\mathrm{GmbH}$. The authors report no other conflicts of interest in this work.

\section{References}

1. Fowles JB, Terry P, Xi M, Hibbard J, Bloom CT, Harvey L. Measuring self-management of patients' and employees' health: further validation of the Patient Activation Measure (PAM) based on its relation to employee characteristics. Patient Educ Couns. 2009;77(2009):116122. doi:10.1016/j.pec.2009.02.018

2. Grady PA, Gough LL. Self-management: a comprehensive approach to management of chronic conditions. Am J Public Health. 2014;104(8): e25-31. doi:10.2105/AJPH.2014.302041

3. Panagioti M, Richardson G, Small N, et al. Self-management support interventions to reduce health care utilisation without compromising outcomes: a systematic review and meta-analysis. BMC Health Serv Res. 2014;14:356. doi:10.1186/1472-6963-14-356

4. Kaptein AA, Fischer MJ, Scharloo M. Self-management in patients with COPD: theoretical context, content, outcomes, and integration into clinical care. Int J Chron Obstruct Pulmon Dis. 2014;1(9):907917. doi:10.2147/COPD.S49622

5. Korpershoek Y, Bos-Touwen ID, de Man-van Ginkel JM, Lammers JW, Schuurmans MJ, Trappenburg J. Determinants of activation for self-management in patients with COPD. Int J Chron Obstruct Pulmon Dis. 2016;1(11):1757-1766. doi:10.2147/COPD.S109016 
6. Rademakers J, Maindal HT, Steinsbekk A, Gensichen J, Brenk-Franz K, Hendriks M. Patient activation in Europe: an international comparison of psychometric properties and patients' scores on the short form Patient Activation Measure (PAM-13). BMC Health Serv Res. 2016;16:570. doi:10.1186/s12913-016-1828-1

7. Bos-Touwen I, Schuurmans M, Monninkhof EM, et al. Patient and disease characteristics associated with activation for self-management in patients with diabetes, chronic obstructive pulmonary disease, chronic heart failure and chronic renal disease: a cross-sectional survey study. PLoS One. 10(5):e0126400. doi:10.1371/journal. pone. 0126400

8. Leventhal H, Phillips LA, Burns E. The Common-Sense Model of Self-Regulation (CSM): a dynamic framework for understanding illness self-management. $J$ Behav Med. 2016;39(6):935-946. doi:10.1007/s10865-016-9782-2

9. Leventhal HL, Brissette I, Leventhal EA. Common-sense model of self-regulation of health and illness. In: Cameron LD, Leventhal H, editors. The Self-Regulation of Health and Illness Behaviour. London: Routledge; 2003:42-65.

10. Tiemensma J, Gaab E, Voorhaar M, Asijee G, Kaptein AA. Illness perceptions and coping determine quality of life in COPD patients. Int J Chron Obstruct Pulmon Dis. 2016;11:2001-2007. doi:10.2147/ COPD.S109227

11. Schuurmans H, Steverink N, Frieswijk N, Buunk BP, Slaets JP, Lindenberg $\mathrm{S}$. How to measure self-management abilities in older people by self-report. The development of the SMAS-30. Qual Life Res. 2005;14(10):2215-2228. doi:10.1007/s11136-005-8166-9

12. Benzo RP, Abascal-Bolado B, Dulohery MM. Self-management and quality of life in chronic obstructive pulmonary disease (COPD): the mediating effects of positive affect. Patient Educ Couns. 2016;99:617-623. doi:10.1016/j.pec.2015.10.031

13. Greiner W, Weijnen T, Nieuwenhuizen M, et al. A single European currency for EQ-5D health states. Results from a six country study. Eur $J$ Health Econ. 2003;4(3):222-231. doi:10.1007/s10198-003-0182-5

14. Tsang S, Royse CF, Terkawi AS. Guidelines for developing, translating, and validating a questionnaire in perioperative and pain medicine. Saudi J Anaesth. 2017;11:S80-S89. doi:10.4103/sja.SJA_203_17

15. Anthoine E, Moret L, Regnault A, Sbille V, Hardouin JB. Sample size used to validate a scale: a review of publications on newlydeveloped patient reported outcomes measures. Health Qual Life Outcomes. 2014;12:176. doi:10.1186/s12955-014-0176-2
16. Schwarzer R, Jerusalem M. Generalized self-efficacy scale. In: Weinman J, Wright S, Johnston M, editors. Measures in Health Psychology: A User's Portfolio. Causal and Control Beliefs. Windsor, UK: NFER-NELSON; 1995:35-37.

17. Broadbent E, Wilkes C, Koschwanez H, Weinman J, Norton S, Petrie KJ. A systematic review and meta-analysis of the brief illness perception questionnaire. Psychol Health. 2015;30(11):1361-1385. doi:10.1080/08870446.2015.1070851

18. Bode C, de Ridder DT, Bensing JM. Preparing for aging: development, feasibility and preliminary results of an educational program for midlife and older based on proactive coping theory. Patient Educ Couns. 2006;61(2):272-278. doi:10.1016/j.pec.2005.04.006

19. R Core Team. R: A Language and Environment for Statistical Computing. Vienna, Austria: R Foundation for Statistical Computing; 2016. URL: https://www.R-project.org/.

20. Talboom-Kamp EP, Verdijk NA, Kasteleyn MJ, et al. High level of integration in integrated disease management leads to higher usage in the e-vita study: self-management of chronic obstructive pulmonary disease with web-based platforms in a parallel cohort design. $J$ Med Internet Res. 2017;19(5):e185. doi:10.2196/jmir.7037

21. Weldam SW, Lammers JW, Decates RL, Schuurmans MJ. Daily activities and health-related quality of life in patients with chronic obstructive pulmonary disease: psychological determinants: a crosssectional study. Health Qual Life Outcomes. 2013;5(11):190. doi:10.1186/1477-7525-11-190

22. Newman S, Steed E, Mulligan K. Chronic Physical Illness: Self Management and Behavioural Interventions. McGraw-Hill Professional Publishing; 2008.

23. Llewellyn CD, Ayers S, McManus C, et al., Eds. Cambridge Handbook of Psychology, Health and Medicine. 3rd. Cambridge: Cambridge University Press; 2019. 458460

24. Thoolen B, de Ridder D, Bensing J, Gorter K, Rutten G. Beyond good intentions: the development and evaluation of a proactive selfmanagement course for patients recently diagnosed with type 2 diabetes. Health Educ Res. 2008;23(1):53-61. doi:10.1093/her/ cyl160

25. Kroese FM, Adriaanse MA, Vinkers CD, van de Schoot R, de Ridder DT. The effectiveness of a proactive coping intervention targeting self-management in diabetes patients. Psychol Health. 2013;29 (1):110-125. doi:10.1080/08870446.2013.841911

\section{Publish your work in this journal}

The International Journal of COPD is an international, peer-reviewed journal of therapeutics and pharmacology focusing on concise rapid reporting of clinical studies and reviews in COPD. Special focus is given to the pathophysiological processes underlying the disease, intervention programs, patient focused education, and self management protocols. This journal is indexed on PubMed Central, MedLine and CAS. The manuscript management system is completely online and includes a very quick and fair peer-review system, which is all easy to use. Visit http://www.dovepress.com/testimonials.php to read real quotes from published authors. 